\title{
The Pragmatic Knowledge of Iranian EFL Learners in Using Face Keeping Strategies in Reaction to Complaints at Two Different Levels
}

\author{
Akram Azarmi (Corresponding author) \\ Bostan Abad Branch, Islamic Azad University, Bostan Abad, Iran \\ E-mail: akramazarm@yahoo.com
}

Biook Behnam

Tabriz Branch, Islamic Azad University, Tabriz, Iran

E-mail: Biook_Behnam@yahoo.com

Received: July 7, 2011

Accepted: August 22, 2011

Published: February 1, 2012

doi:10.5539/elt.v5n2p78

URL: http://dx.doi.org/10.5539/elt.v5n2p78

\begin{abstract}
The purpose of this study was to investigate the ability of the upper intermediate and the intermediate learners in keeping face in different complaint situations. Complaint is the expression of the speaker displeasure or annoyance as a reaction to a past or ongoing action, the consequences of which affect the speaker unfavorably (Olshtain \& Weinbach, 1987). Brown and Levinson (1978) categorized complaints as Face-Threating Act. Forty learners were selected based on their scores on a proficiency test. They completed a Discourse Completion Test which included different complaint scenarios. Their responses were analyzed on the basis of four complaints categories of Olshtain and Weinbach (1987) and three complaint categories of De Capua's (1998). Then, their answers were compared with Brown and Levinson's (1978) politeness theory for the face keeping strategies. The findings revealed that the upper intermediate learners and the intermediate learners used different types of speech acts in each situation and that at low levels some degree of pragmatic awareness should be presented. The study provided some pedagogical implications for the field of EFL teaching and syllabus designing.
\end{abstract}

Keywords: Pragmatic, Face keeping strategies, Complaint speech act, Discourse Completion Test

\section{Introduction}

In order to be successful in communication, it is essential for language learners to know not just grammar and text organization but also pragmatic aspects of the target language (Bachman, 1990). Communicative action includes not only speech acts - such as requesting, greeting, and so on - but also the ability to use language forms in a wide range of situations, including the relationships between the speakers involved and the social and cultural context of the situation and so on. Through speech acts such as requesting and complaining, one shapes the utterances and with politeness makes use of these utterances in the best way.

One type of these speech acts is complaining which occurs when a speaker reacts with displeasure or annoyance to an action that has affected the speaker unfavorably (Olshtain \& Weinbach, 1987).Complaint is an expression of a psychological state of being dissatisfied or unhappy about something which demands special kind of speech act and different kind of face keeping strategies. However, sometimes people use speech acts that threat face; Brown and Levinson (1987) categorized complaint as one of the face-threating acts that have strong potential for disturbing the state of personal relationship.

It is assumed that some pragmatic knowledge is universal. Non native speakers get a considerable amount of pragmatic knowledge from their L1 and other pragmatic aspects may be successfully transferred from the learners' L1 too. To start with the pragmatic universals, learners know that conversations follow particular organizational principles, participants have to take turns at talk, and that conversations and other speech events have specific internal structures (Kasper, 1997).

The present research was intended to examine the pragmatic knowledge of Iranian EFL learners in using face keeping strategies in reaction to complaints.

A large number of theoretical and empirical books and articles concerning linguistic politeness and the notion of face have been published in the last decades. In most of the studies, the politeness has been conceptualized 
especially as strategic conflict-avoidance or as strategic construction of cooperative social interaction.

\section{Review of the Related Literature}

Although not much research has been conducted on complaints in Iranian context but recently Salmani-Nodoushan (2006), in his paper, conversational strategies in Farsi complaints: The case of Iranian complainers, studied the effects of complainers' sex, age, perceived situational seriousness, and social class on the use of conversational strategies in their complaining behavior, 465 subjects of varying age, sex, and social class were observed and tape recorded in spontaneous conversation by 25 field workers. The four strategies under study were: (1) expressing emotions, (2) dealing with complaint situation, (3) providing rhetoric for argument, and (4) manipulating development of conversation. He explained that this finding was rather odd. When the topic of complaint was a serious matter, researchers logically expect more complaint, but the subjects of the study behaved in the opposite way.

Allami (2006) in his paper, A sociopragmatic analysis of griping: The case of Iranian students, argued that unlike direct complaint, "griping" is a non-face-threatening speech act in which the party or object of complaint is not present. While direct complaint, as defined by Brown and Levinson (1987), is a face-threatening act, it has been claimed that griping carries no face threat. Furthermore, unlike direct complaint, which is used to call for negotiation, griping is used as a means to invoke commiseration. He studied the responses provided for griping in terms of six major categories: 1) topic switch/blank reply, 2) question, 3) contradiction, 4) joking/teasing, 5) advice, 6) agreement/ commiseration. The subjects in this study comprised 50 university students, the data had been collected through a 'Discourse Completion Task' (DCT). Each item included six responses (x1, x2, x3, x4, x5, x6) in line with the six categories of griping responses [1) topic switch, 2) questions, 3) contradiction, 4) joking/teasing, 5) advice/lecture and 6) commiseration]. Five items were griping on different subject matters among friends, five items among family members, another five on casual matters among strangers and the last five on deeper, more challenging matters (e.g. political) among strangers. The findings revealed that in response to griping, Iranian students, most of the time, feel obliged to further conversation and maintain solidarity through the use of the supportive speech act of commiseration. However, they do not support Boxer's finding that women participate more in troubles-talks than men, or that women mostly commiserate with griping while men contradict or give advice.

Research has shown that the realization of complaints varies across speakers from different cultures. Tanck (2002) conducted research that aimed to compare the pragmatic competence of adult ESL speakers to that of adult native English speakers when performing the speech act of complaints and refusals. To generate data for this study, the subjects were given a "Discourse Completion Test" where in they wrote their responses to six prompts. He used six situation of DCT that just two situation related to complaints. Responses of native English speakers are reviewed for evidence of common components of speech act sets to establish a set of baseline responses.

The results of this study revealed that while native and nonnative speakers often produce almost identical speech act set components for complaints and refusals, the quality of the components produced by nonnative speakers differ markedly from those made by the native speaker's sample. The nonnative speakers' responses, though generally linguistically correct, lack the pragmatic elements that allow these face-threating acts of complaint and refusal to be well received by the hearer.

Another cross-cultural study was Moon's (2001) study who worked on the speech act of complaint as produced by 129 native and nonnative speakers of English. The (DCT) gave four prompts that provide the subjects with complaint situations. The data collected from the subjects were analyzed based on Olshtain and Weinbach. The scale of the severity of complaints consists of five categories: Below the level of Reproach, Expression of annoyance or disapproval, Explicit complaint, Accusation and warning, and Immediate threat. These are defined in terms of the speaker's position with respect to the hearer's face and in terms of its linguistic features. The severity of complaints in this study consists of four categories that focus more on the linguistic features of the subjects' utterances. The results of this study apparently showed that nonnative speakers were not always successful in complaint and in communication, in general. These failures of nonnative speakers in complaints were primarily caused by their grammatical and linguistic limitations, but mainly caused by the limitation of sociopragmatic knowledge. Nonnative speaker subjects do not always make complaints following the appropriate ways of NS's complaints. They tend to make complaints in a more explicit way, whereas native subjects use more implicit ways of complaints.

Arent (1996) compared the relative frequency of the performance and avoidance of oral complaints by 22 Chinese learners and 12 native speakers (NSs) of American English. The participants were enrolled in a major U.S. university and were asked to respond to three problematic situations that were set in the same university housing complex where all of the respondents lived. In response to naturalistic observations, an elicitation instrument was designed to elicit English complaints through audio taped, closed role plays, combined with perceptions of 
situational seriousness and verbal report data. In addition to the three basic situations, an up grader was added to each situation so that participants would be forced once again to make a decision about whether to perform a complaint or not. An up grader was an action or response (verbal or non-verbal) that increases the relative value of the rank of the imposition (i.e., the severity of the situation). Data was collected and analyzed through three variable 1) perception of seriousness of situation; 2) type of response for the original situation; and 3) type of response for the upgrade. The instrument did not presuppose the performance of a face-threatening act (FTA) and allowed each participant to respond to the situations verbally or nonverbally, while controlling for the effects of social distance, power, and type of social contract. The questionnaire was translated into Mandarin Chinese to minimize the amount of misunderstanding with the Chinese participants. The data tentatively suggest that sociopragmatic decision-making for Chinese learners and NSs of American English appeared to be associated with individual perceptions of situational seriousness and with culturally-conditioned perceptions of the flexibility of explicit social contracts.

The findings indicated that American and Chinese participants differed significantly in the frequencies of complaint performance. This can perhaps be explained through differing levels of the perception of seriousness of each situation and through different understandings of the flexibility of explicit social contracts.

Olshtain and Weinbach (1987) studied the speech act of complaint as produced by native and non-native speakers of Hebrew. The researchers developed five categories of speech acts that were based on severity of the complaint for a specific scenario, in which one colleague had waited for another colleague, who arrived late to a scheduled appointment.

The five categories were: (1) below the level of reproach, "No harm done, let's meet some other time;" (2) disapproval, "It's a shame that we have to work faster now;" (3) complaint, "You are always late and now we have less time to do the job;" (4) accusation and warning, "Next time don't expect me to sit here waiting for you;" and, (5) threat, "If we don't finish the job today I'll have to discuss it with the boss" (p. 202). The results of this study indicate that all members of the sample in both groups (native and nonnative speakers of Hebrew) make use of the five strategies mentioned above. However, in this particular scenario, the sample shows greater tendency to use the middle three strategies in this scale, i.e., disapproval, complaint and accusation. The two extreme strategies, i.e., "below the level of reproach" and "threat" are found to be less frequently used.

Olshtain and Weinbach (1987) also discuss the preconditions that are necessary for the speech act of complaints to take place. These factors present well the speech events that indicate what makes the participants talk, what they are talking about, and what the purpose of complaining is. DeCapua (1998) studied the speech act of complaint as produced by 50 native speaker of German who were American field service students in the United state for a year a year of high school and all the participants wrote answers for DCT. DeCapua constructed five situations that were likely to elicit a complaint and instructed the subjects to respond to the situations as though they were actually engaging in a conversation.

DeCapua classified complaint responses as: 1) statement of problem; 2) request forrepair; 3) demand for repair; 4) justification; and 5) criticisms.

Study indicated that Germans showed a preference for requests for repair, justifications, and criticism more than Americans who tend to avoid these strategies. Also female respondents made more request for repair than males and transfer errors from German into English sometimes produced. Overly demand complaint as "you must pay for a new one" rather than should.

Sahragard (2001) in his paper, A cultural script analysis of a politeness feature in Persian, made an investigation of what was this all-pervading feature of the Iranian culture. He used an approach that is based on the fact that in all human languages there are some basic terms functioning as bases for other concepts. In other words, the former concepts are primitives. These primitive concepts are used to describe cultural rules of speaking or 'cultural scripts'. Thus this study took a cultural script approach to describe the Persian concept of ta'arof. The elicitation methods have been used to gather instances of ta'arof and also to know the views of the native speakers on this issue. The methods were questionnaires, interviews, and observation. 220 male and female participants answered questions in the questionnaires and 27 university lecturers participated in the interviews.

The findings of the analysis were then used as bases for the description of ta'arof in the cultural script approach. The English equivalents (since the study is written in English, not Persian) are here used to describe ta'arof and its constituents in Persian. Ta'arof can be the manifestation of: 1- Adab (politeness), 2- Ehteraam (respect), 3Rudarbaayesti (being shy or ceremonious). 4- Tavaazo? (humility) and 5- mehmaan-navaazi (hospitality).

In fact, Koutelaki (as cited in Sahragard, 2001) argues that any description or analysis of the Iranian politeness 
system without a reference to this concept will be deficient and incomplete. So a typical person who, knows ta'arof and uses it reasonably, is polite in the use of his language and behavior, respects others, is humble in his words and actions, harasses his desires, and is openly generous and cordial towards others. Adab is sometimes used for translating English words such as' politeness', 'courtesy', and 'respect', it stands for a uniquely Islamic (Iranian) concept which cannot be satisfactorily explained by comparing it with any of these supposed English equivalent.

Ta'arof can be the manifestation of:

1- Adab (politeness)

2- Ehteraam (respect)

3- Rudarbaayesti (being shy or ceremonious)

4- Tavaazo?(humility)

5- Mehmaan-navaazi (hospitality)

1- Adab

Adab is an important concept in Islamic culture. As such it is basically a moral issue. Glasse(as cited in Sahragard,2001,p.405) defines it as 'courtesy, politeness, propriety, morals, and literature' .

\section{2- Ehteraam}

The most pivotal aspect in human relations among Iranians is the concept of Ehteraam. In fact, it is most readily replaced with other concepts suggesting politeness. Any polite behavior can be regarded as the cause for Ehteram.

3- Rudarbaayesti (being shy or ceremonious)

It is defined as considering' Hayaa', 'shame' or being embarrassed' or its synonym 'Sharm' ,'Shame' from saying or doing something in fear of being misinterpreted as not accounting for other person's respect.

4- Tavaazo? (humility)

Although the word is purely Arabic, it is more frequently used in Persian than other original Persion words. This may be due to the fact that Tavazo? is basically a religious concept. Persian-English dictionary assign to it two English words: 'humility' and 'modesty'.

5- Mehmaan-navaazi (hospitality)

The characteristics of Mehmaan-navazi, hospitality, can be exemplified in the typical exchange of expressions and nonverbal that the hosts use towards the guests.

\section{Methodology}

\subsection{Participants}

The participants of the study consisted of 40 students, 20 of whom were intermediate EFL learners and 20 upperintermediate EFL learners including 35 female and 5 male learners. All of the learners were selected from English teaching and translating classes at Islamic Azad University-Tabriz Branch whose age ranged between 19-25 years old. Their first language was Turkish except for three learners who were Persian native speakers.

\subsection{Instruments}

To select two groups of EFL learners at the intermediate and the upper intermediate levels, a proficiency test of PET (Preliminary English Tests, 2004) including questions in reading and writing was given. The DCT questionnaire which was used for this study included five situations which were taken from Moon (2001) and one situation from Tank (2002), all the subjects were given the same DCT test (see appendix A). The Discourse Compilation Test (hence for DCT) is a form of questionnaire describing some natural situations to which the respondents were expected to react making complaints.

\subsection{Design}

This study adapted a survey based study, which is descriptive statistics for analyzing complaints and for face keeping strategies. To investigate pragmatic knowledge of Iranian EFL learners in different complaint situations, Olshtain and Weinbach's (1987) four complaints categories and De Capua's (1998) three complaint categories were used. For estimating the kind of face keeping strategies, the responses of the learners were studied with Brown and Levinson's (1987) politeness theory.

\subsection{Data Collection}

To collect data for this study, two main instruments were used: proficiency test (PET) and DCT. In DCT 
questionnaire, the subjects were requested to answer some demographic information including age, level of education and first language.

The prompts were as follows.

Situation \#1.

One of your American friends is visiting you for the weekend. Before he/she arrives, your clean the kitchen. Your friend arrives. Then, you need to run to the shopping because you forgot to buy something. You tell your friend to make him/her comfortable. When you come back home, you see that your friend has left a big mess in the kitchen.

Situation \#2.

You want to buy tickets for a concert. You go to the ticket office and have to wait in a long line with other people. The tickets are almost sold out. You have been waiting in line for almost two hours. While you are standing in line, a $\mathrm{man} /$ woman who is about your age tries to cut in line in front of you.

Situation \#3.

You have worked for your boss since last year. You think you get along well. Every year, your boss writes a review of your job performance. This year, you find out that your boss is giving you a bad review. You think the review is not fair.

Situation \#4.

Last fall, you registered for courses. You went to your academic advisor in order to get advice. That was the first time and the only time you met the advisor. You asked the advisor what courses you should take during the fall term. The advisor told you what courses to take. After the fall term, you find out that one of the courses was not necessary for you. Instead, you have to take a different course now during the summer term in order to fulfill the required courses.

Situation\#5.

Yesterday you placed an order at the photocopy shop for 10 bound copies of your thesis. Today you must deliver all 10 copies to your evaluation committee by 12:00 noon. When you go to the photocopy shop at 11:00A.M to pick up your booklets, the clerk, whom you recognize from one of your classes, seems confused and unaware of your request.

\section{Results}

In this part of the study, the analysis and frequency of speech act of complaints at the intermediate and the upper intermediate levels are presented for each situation.

\section{Situation 1}

In response to this situation, in which the speaker is complaining to a friend who has messed up the speaker's room, the majority of the intermediate and the upper intermediate learners tended to apply similar complaint components, but with different levels of frequency. The frequency of complaints for this situation is summarized in Table 1 and Figure 1 below.

In this situation five components were typically found in the intermediate learners' production of complaints among which the obvious ones were below the level of reproach with the frequency of (50\%), expression of annoyance with the frequency of $(20 \%)$, request for repair with the frequency of $(15 \%)$ and explicit complaint with the frequency of $(5 \%)$.

The remarkable components in the upper intermediate level were Expression of annoyance or disapproval (30\%), justification $(20 \%)$, request for repair $(25 \%)$ and below the level of reproach $(25 \%)$. So the intermediate learners were very modest in complaining to a friend in comparison to the upper intermediate learner.

\section{Situation 2}

In Table 2 the frequencies of complaints to a stranger have been summarized.

The intermediate and the upper intermediate used different types of complaints to a stranger. The use of explicit complaint was (45\%), expression of annoyance (35\%), accusation and warning (15\%) and below the level of reproach $(5 \%)$.The intermediate learners produced more direct complaints without trying to avoid conflict.

In the upper intermediate level, they used accusation and warning (30\%), request for repair $(30 \%)$, expression of annoyance (20\%), explicit complaint (15\%) and justification (5\%).

Situation 3 
In complaining to the boss two groups used different types of complaints which are shown in Table 3. In complaining to the boss, expression of annoyance or disapproval $(30 \%)$ and explicit complaint $(20 \%)$ without avoiding threat to a face at the intermediate level were apparent. It seems that the intermediate learners did not regard power and social distance even when they used request for repair (30\%) and accusation and warning (15\%).Most of the upper intermediate learners used request for repair (40\%) and justification to the boss $(25 \%)$. They used expression of annoyance (30\%) and below the level of reproach $(5 \%)$.

Situation 4

The complaints to the advisor were one of the familiar situations for learners and their responses are presented in Table 4. As it is easily noticeable from the Table 4, in the intermediate level the explicit use of complaint were $(45 \%)$, below the level of reproach (20\%), request for repair $(25 \%)$ and accusation and warning $(10 \%)$.

In complaining to the advisor, the use of below the level of reproach (35\%), accusation and warning (20\%), request for repair (35\%) and justification (10\%) were the most favored strategies in the upper intermediate level.

\section{Situation 5}

Table 5 reveals that in the intermediate level expression of annoyance or disapproval (40\%), request for repair (25\%), explicit complaint $(25 \%)$ and accusation and warning (10\%) were apparent. In addition to the power relationship that exists between clerk and customer, the clerk is a classmate thus shares a relationship that is familiar and close in terms of status and social distance. In the upper intermediate level, the harshness of speech was reduced by using other types of complaints, i.e. below the level of reproach (10\%), expression of annoyance (35\%), request for repair $(45 \%)$ and justification (10\%).

\section{Discussion}

This section provides the answers to four research questions posed in this study. To organize the answers, the questions themselves are used.

What are the different complaint strategies that Iranian EFL learners used in different situations?

Are there any differences between intermediate and upper-intermediate Iranian EFL learners in using complaint strategies?

Examining the answers was based on the seven types of complaining strategies.

\section{Complaints}

Blow the level of reproach was the first complaints which was used by the intermediate groups. The differences between two groups of the learners indicated that the upper intermediate learners used this type of complaints in different situations than the intermediate learners due to being indirect complaint one. According to Sauer (2000as cited in Moon, 2001)

The directness of complaining can be controlled by the speaker. The speaker can use different linguistic forms and nonverbal signals in order not to threaten the hearer's face and to remain polite. The perception of threatening and politeness, however, is not always the same. It varies cross-culturally. (p. 4)

This type of complaint may be more acceptable in Iranian context, as it is clear from the examples; this type of complaint is indirect and similar to Ta' arof in Iranian context.

Boxer and Pickering (1995) in their study said that "nonnative speakers may unintentionally perform inappropriate complaints. Native speakers, tend to think of direct rather than indirect complaint" (p. 56). However, the way in which individuals speak to each other is heavily conditioned by variables such as: whether interlocutors are friends or co-workers, whether they are speaking at home or in the workplace, whether they are men or women, all constrain to some degree the kind of verbal exchange that takes place.

The second type of complaints was the Expression of annoyance or disapproval which in first glance seems to be explicit complaints. In this type, the complainer did not blame a person but express a general complaint. The frequencies of this strategy were different among two levels and both group used this strategy in majority of the situations.

Both groups of the learners used this complaint in similar situations and expressed their complaint by saying general terms. Moon (2001) expressed that:

Nonnative speakers are not always successful in complaint. The failures of nonnative speakers in complaints are primarily caused by their grammatical and linguistic limitations, but mainly caused by the limitation of sociopragmatic knowledge. Nonnative speaker subjects do not always make complaints following the appropriate 
ways of NS's complaints. They tend to make complaints in a more explicit way, whereas native subjects use more implicit ways of complaints. (p. 22)

In the case of explicit complaint or direct complaint, the intermediate learners used it in all situations regardless of considering the power or distance. Due to being a written form of interaction, most of the learners may not consider the power or distance and imposition and they expressed their answers to complete the answers parts. Using of other types of methods such as interview or other methods will result in more naturalistic responses.

Farnia, Buchheit, \& Salim (2010) found that" in a situation where hierarchy and social status were expected to be important, as in Malaysia an eastern non-egalitarian society where keeping face was more acceptable, Malaysian used more complaints than their American counterparts"(p. 22). In Iranian context which is an eastern context, this kind of complaints was not used so much as Sahragard (2000) said that the most permanent feature in Persian culture is Ta'arof and in most of situations it is observable.

Accusation and warning was used in almost all the situations. The result of this study contract with Allami (2006) findings that Iranian students, most of the time, feel obliged to further conversation and maintain solidarity through the use of the supportive speech act of commiseration.

It is generally believed that the speech act of complaint is face threating to the hearer. "When the speaker makes direct complaints, he/she is more likely to threat the hearer's face, or say hurt his/her feelings and hence damage the relationship between them "(Sauer, 2000 and Boxer, 1993 as cited in Moon, 2001, P. 4).

The intermediate learners did not use Requests for repair in situation 2 although the upper intermediates learners in most of cases used this type of complaint.

The frequency of request for repair was high between upper intermediate learners. From this one may concluded that if the learners poses sufficient linguistic knowledge, they may produce indirect way of complaining.

The intermediate learners avoided Justification because for performing this type of complaint one must have the ability to use different indirect type of complaining speech act.

None of the group used Criticisms, Sauer (2000 as cited in Moon, 2001) discusses that the speech act of complaints is different from the speech act of criticism. According to Sauer "criticism is stronger than complaints, in that the speaker's responses are much more blunt, contemptuous, and direct" (p .4).

More recently Salmani-Nadoshan (2006) claimed that the complaining of Iranian people are different because from childhood Iranian people learn not to protest against the friend or elder people.

The reason for this difference can be found in the norms that shape the Iranian community. Iranians are culturally grown up in such a way as to avoid conversations that result in conflict. They are told by our parents and teachers, from childhood to adolescence and beyond, that conflict and dispute is to be avoided.

It is not very odd, therefore, to observe that Iranian complainers continue repeating their complaints about non-serious matters, until they realize that the person is about to react angrily, at that time they stop complaining. (p. 13)

Although the learners were EFL, Iranian forms of complaint were obvious in their answers, especially for the intermediate learners who avoided continuing their complaints. In most of the situations, this group wrote short answers for each situation.

There is close relationship between using complaining speech acts and politeness for mitigating threat to hearer's face. To show this relationship these findings discussed below for the types of face keeping strategies.

\section{Face}

In this part of the study, face keeping strategies in five situations were presented.

What kind of face-keeping strategies are used by Iranian EFL learners in reaction to complaints?

Are there any differences between intermediate and upper-intermediate Iranian EFL learners in using face keeping strategies?

For showing cultural aspect and importance of it in Iran, different types of politeness strategies in Iran were used. Adab is sometimes used for translating English words such as' politeness', 'courtesy', and 'respect', it stands for a uniquely Islamic (Iranian) concept which cannot be satisfactorily explained by comparing it with any of these supposed English equivalent. Ta'arof can be the manifestation of: 1-Adab (politeness), 2- Ehteraam (respect), 3Rudarbaayesti (being shy or ceremonious). 4- Tavaazo? (humility) and 5- mehmaan-navaazi (hospitality) (Sahragard, 2000). 
Below the level of reproach in which the speaker avoids explicit mention of the offensive act by means of various remarks without directly blaming the interlocutor was the most favored strategy in the situation 1.This is probably in line with positive politeness, which shows you recognize that your hearer has a desire to be respected. In terms of Iranian politeness, it is likely the same as mehmaan-navaazi (hospitality) that is exemplified in the typical exchange of expressions and nonverbal behaviours that the hosts use towards the guests.

The remarkable component in the upper intermediate level was Expression of annoyance or disapproval that is realizations of disapproval by means of indirect or vague indications. In line with positive face saving, it shows that something has been violated without holding the interlocutor directly responsible. In comparison to the upper intermediate learners, the intermediate learners were very modest in complaining to the friend. It is maybe the same as - Rudarbaayesti (being shy or ceremonious) in Iranian culture.

In a complaining to stranger (i.e. situation 2) the intermediate learners used an explicit complaint which carries potential consequences for the interlocutor. It is baldly threat the face.

Hence, the majority of the upper intermediate learners used accusation and warning and request for repair.

These findings in this situation reveal that learners feel free to produce desired complaints, when they did not know people. They did not consider the status and power relationship, if they feel that they have right.

In Situation 3, most of the intermediate learners expressed their annoyance and used request for repair to the boss. The upper intermediate learners used request for repair and expression of annoyance, that were baldly a threat to the hearer's face, because of inadequate pragmatic knowledge. It is not in line with Iranian form of Ehteraam (respect).

In Situation4, the upper intermediate subjects used a mixture of complaints speech act; the amount of below the reproach was higher. It probably shows that in Iran culture the teachers have a superior position and the students respect them. In Iranian culture it's called Tavaazo? (humility) . Due to their poor knowledge in pragmatic use, the intermediate learners violated this kind.

In Situation 5 the relationship is similar to situation 1 but as a customer which has the right to complaint to the clerk, the upper intermediate learners used Request for repair, which baldly threat the face and probably far from Adab (politeness) in Iranian context. Expression of annoyance that were used by the intermediate learners was threating behavior.

\section{Conclusion}

This paper attempted to integrate a number of issues that arise in pragmatics. The major purpose of this study was to shed light on the complaint speech act through which politeness behavior of students revealed. The explicit complaints of the intermediate learners asserted the point that, in their early learning stages, learners may not be able to use pragmatic strategies because they have not yet acquired the necessary linguistic means. But when they acquire enough linguistic knowledge, learners will use the pragmatic strategies. Failures to perform proper complaints in the upper intermediate level were largely attributable to cultural differences, pragmatic transfer, and limitation of linguistic competence. According to Lin (2007) Knowledge about cultures, both general and specific, provides insights into the behaviors of different groups. A specific culture is shared in which individuals' understandings, judgment and evaluation of what is happening around them should have something in common.

Unfortunately, as finding of this study revealed, the learners do not always make use of their language knowledge e.g. they did not use their L1 knowledge. It is well known from educational psychology that students do not always transfer their L1 knowledge and strategies to new tasks. Learners often tend towards surface interpretation, taking utterances at face value rather than inferring what is meant from what is said and under using context information (Kasper, 1981). The differences between the upper intermediate and the intermediate learners revealed that in spite of the relatively long period of learning English, the Iranian learners of English did not demonstrate sufficient socio-pragmatic skills that qualify them to produce appropriate complaint in English.

\section{Implications}

Based upon the analysis and discussion of this study, the following pedagogical statements can be made. Even fairly advanced language learners' communicative acts regularly contain pragmatic errors, or deficits, in that they fail to convey or comprehend the intended illocutionary force or politeness value. Therefore, there is a need for instruction to focus on the pragmatics of the language, and researchers in this area generally point to the positive impact of instruction aimed at raising learners' pragmatic awareness (Kasper 1997).

It is anticipated that the findings of the present study will add to the body of literature in contrastive pragmatic study in demonstrating the differing behaviors of two contrasting cultures in terms of expressing complaints in formal and informal situations, and the possible implications of English study on speech acts. Such comparisons may help 
applied linguists, and most particularly second / foreign language teachers and syllabus designers to account for deviations that may characterize nonnative speakers' performance and to suggest the most salient strategies that may help the learners to acquire the pragmalinguistic aspects of the target language.

The field of translation, by making the translators aware of cultural differences, may also benefit from this. As a result we would have better translation works in future. Teachers should make Iranian learners aware about the cultural differences so that when learners are reading an English book, they don't become surprised about the way the complaint are being made in that language.

\section{References}

Arent, R. (1996). Sociopragmatic decisions regarding complaints by Chinese learners and of NSs American English. Journal of Applied Linguistics, 1, 125-147

Allami, H. (2006). A sociopragmatic analysis of griping: The case of Iranian students. Asian EFL Journal, 1, 59-76

Afghari, A., \& Karimnia, A. (2007). A contrastive study of four cultural differences every day conversation between English and Persian. Iran Intercultural Communication Studies, XVI(1), 243-250

Backman, L. (1990). Fundamental considerations in language testing. New York: Oxford University Press.

Bargiela-Chiappini, F. (2003). Face and politeness: New (insights) for old (concepts). Journal of Pragmatics, 35(11), 1453-1469. http://dx.doi.org/10.1016/S0378-2166(02)00173-X

Bharuthram, Sh. (2003). Politeness phenomena in the Hindu sector of the South African Indian English speaking community.

Blas Arroyo, J. (2011). From politeness to discourse marking: The process of pragmaticalization of muy bien in vernacular Spanish.

Boxer, D., \& Pickering, L. (1995). Problems in the presentation of speech acts in ELT materials: The case of complaints. ELT Journal, 49(1), 44-58. http://dx.doi.org/10.1093/elt/49.1.44

Boxer, D. (2002). Nagging: The familial conflict arena. Journal of Pragmatics, 34, 49-61

Brown, P., \& Levinson, S. (1987). Politeness: Some universals in language usage. Cambridge: Cambridge University Press.

Brown, G., \& Yule, G. (1983). Discourse analysis : Cambridge text book in linguistic. Cambridge: Cambridge University Press.

Burdelski, M. (2010). Socializing politeness routines: Action, other-orientation, and embodiment in a Japanese preschool. Journal of Pragmatics, 42(6), 1606-1621. http://dx.doi.org/10.1016/j.pragma.2009.11.007

Carlo, J., \& Yoo, Y. (2007). How may I help you? Politeness in computer-mediated and face-to-face library reference transactions. Information and Organization, 17(4), 193-231

Carbaugh, D. (2007). Cultural discourse analysis: 5 communication practices and intercultural encounters. Journal of Intercultural Communication Research, 36(3), 167-182

Chen, R. (2001). Self-politeness: A proposal. Journal of Pragmatics, 33(1), 87-106

Conlan, Ch. (1996). Politeness, paradigms of family, and the Japanese ESL speaker. Language Sciences, 18(3-4), 729-742

DeCapua, A. (1988). Complaints: A comparison between German and English. Paper presented at the 1988 TESOL Convention, Chicago, IL, March 11

Eslami-Rasekh, Z. (2005). Raising the pragmatic awareness of language learners. ELT Journal, 59(3), 199-208. http://dx.doi.org/10.1093/elt/cci039

Earley, P. C. (1997). Face, harmony, and social structure, an analysis of organizational behavior across cultures. New York: Oxford University Press.

Eelen, G. (2003). A critique of politeness theories. Journal of Pragmatics, 35, 811-818

Escandell-Vidal, V. (1996). Towards a cognitive approach to politeness. Language Sciences, 18, (3-4), 629-650

Eslami-Rasekh, A., \& Abdolnazarpour, P. (2010). A cross-cultural study of perception of politeness by Iranian and American in request forms. Pakistan Journal of Social Science, 7(2), 164-169

Farnia, M., Buchheit, L., \& Salim, Sh. (2010). I need to talk to you- A contrastive pragmatic study of speech act of complaint in American English and Malaysian. The International Journal of Language Society and Culture, 30, 


\section{$11-23$}

Félix-Brasdefer, C. (2006). Linguistic politeness in Mexico: Refusal strategies among male speakers of Mexican Spanish. Journal of Pragmatics, 38(12), 2158-2187

Grice, P. (1975). Logic and conversation. In: P. Cole, \& J. Morgan (eds.), Syntax and Semantics 3. Speech Acts, 41-58. New York: Academic Press.

Haugh, M., \& Hinze, C. (2003). A metalinguistic approach to deconstructing the concepts of 'face' and 'politeness' in Chinese, English and Japanese. Journal of Pragmatics, 35(10/11), 1581-161

Haugh, M. (2007a). The co-constitution of politeness implicature in conversation. Journal of Pragmatics, 39(1), 84-110. http://dx.doi.org/10.1016/j.pragma.2006.07.004

Haugh, M. (2007b). Emic conceptualisations of (im)politeness and face in Japanese: Implications for the discursive negotiation of second language learner identities. Journal of Pragmatics, 39(4), 657-680

Hatch,E. (1992). Discourse and language education. Cambridge: Cambridge university press.

Hatipoğlu, C. (2007). (Im)politeness, national and professional identities and context: Some evidence from e-mailed 'Call for Papers'. Journal of Pragmatics, 39(4), 760-773

Henry, A., \& Ho, H. (2010). The act of complaining in Brunei-Then and now. Journal of Pragmatics, 42(3), 840-855

Hobbs, P. (2003). The medium is the message: Politeness strategies in men's and women's voice mail messages. Journal of Pragmatics, 35(2), 243-262

Jansen, F., \& Janssen, D. (2010). Effects of positive politeness strategies in business lettersm. Journal of Pragmatics, 42(9), 2531-2548

Jia. W. (1997). Face work as a Chinese conflict-preventive mechanism - A cultural/discourse analysis. Intercultural Communication Studies, VII(1), 1997-8

Ji, sh. (2000). 'Face' and polite verbal behaviors in Chinese culture. Journal of Pragmatics, 32(7), 1059-1062

Kasper, G., \& Farch, C. (1983). Strategies in interlanguage communication. New York: Longman INC.

Kasper, G. (1990). Linguistic politeness: Current research issues. Journal of Pragmatics, 14(2), 193-218

Kasper, G. (1997). Can pragmatic competence be taught? Second Language Teaching \& Curriculum Center, National Foreign Language Center.

Kasper, G. (2000). Data collection in pragmatic research. In Spencer-Otey, H., Culturally speaking: managing report through talk across cultures. (pp. 316-342). London and New York: Oxford University Press.

Laforest, M. (2002). Scenes of family life: Complaining in everyday conversation. Journal of Pragmatics, 34, 1595-1620. http://dx.doi.org/10.1016/S0378-2166(02)00077-2

Leech, G. (1983). Principle of pragmatics. New York: Longman Linguistic Library.

Lin, X. (2007). Cultural dimensions and conversational strategies-Conversational strategies adopted in different cultures and the way to bridge the gap. US-China Foreign Language, 5(4),71-76

Loa, A., \& Howard, K. (2009). Mobilizing respect and politeness in classrooms. Linguistics and Education, 20(3), $211-216$

Mao, R. (1994). Beyond politeness theory: 'Face' revisited and renewed. Journal of Pragmatics, 21(5), 451-486

Marti, L. (2006). Indirectness and politeness in Turkish-German bilingual and Turkish monolingual requests. Journal of Pragmatics, 38(11), 1836-1869

Mills, S. (2009). Impoliteness in a cultural context. Journal of Pragmatics, 41(5), 1047-1060. http://dx.doi.org/10.1016/j.pragma.2008.10.014

Moon, K. (2001). Speech act study: differences between Native and Nonnative speakers' complaint strategies.

Nakane, I. (2006). Silence and politeness in intercultural communication in university seminars. Journal of Pragmatics, 38(11), 1811-1835

Neagu, M. (2007). Politeness and the public sphere. Proceedings of The Conference Public Space vs. Private Space, 3, 422-433

Nevala, M. (2004). Accessing politeness axes: forms of address and terms of reference in early English 
correspondence. Journal of Pragmatics, 36(12), 2125-2160

Nwoye, O. (1992). Linguistic politeness and socio-cultural variations of the notion of face. Journal of Pragmatics, 18(4), 309-328

Olshtain, E., \& Weinbach, L. (1987). Complaints: A study of speech act behavior among native and non-native speakers of Hebrew. In J. Verschueren, \& M. Bertucelli-Papi (Eds.), the Pragmatic Perspective. Amsterdam: John Benjamins. pp. 195-208

Pfister, J. (2010). Is there a need for a maxim of politeness? Journal of Pragmatics, 42(5), 1266-1282

Rose, K., \& Kasper, G. (2001). Pragmatic in language teaching. Cambridge: Cambridge University Press.

Ruhi, R., \& Gu"ler, H. (2007). Conceptualizing face and relational work in (im)politeness: Revelations from politeness lexemes and idioms in Turkish. Journal of Pragmatics, 39(4), 681-711. http://dx.doi.org/10.1016/j.pragma.2006.11.013

Sahragard, R. (2001). A cultural script analysis of a politeness feature in Persian.

Salmani-Nodoushan, M. (2006). Conversational strategies in Farsi complaints: the case of Iranian complainers. Language, Society and Culture, 18

Schmitt. N. (2002). An introduction to applied linguistics. New York: Oxford University Press.

Spencer-Oatey, H. (2002). Managing interpersonal rapport: Using rapport sensitive incidents to explore the motivational concerns underlying the management of relations. Journal of Pragmatics, 34, 529-545

Spencer-Oatey, H. (2007). Identity, face and (im)politeness. Journal of Pragmatics, 39, 635-638

Tanck, S. (2002). Speech act sets of refusal and complaint: A comparison of native and non- native English speakers' production.

Terkourafi, M. (2011). Thank you, sorry and please in Cypriot Greek: What happens to politeness markers when they are borrowed across languages? Journal of Pragmatics, 43(1), 218-235

Terkourafi, M. (2006). Politeness: J. Watts Richard. Journal of Pragmatics, Volume 38(3), 418-428

Traverso, V., \& Heinemann, T. (2009). Complaining in interaction. Journal of Pragmatics, 41, 2381-2384. http://dx.doi.org/10.1016/j.pragma.2008.10.006

Umar, A. (2006). The speech act of complaint as realized by advanced Sudanese learners of English. Journal of Educational \& Social Sciences \& Humanities, 18(2), 9-40

Vilkki, L. (2001). Politeness, face and facework: Current issues. A Man of Measure Festschrift in Honour of Fred Karlsson, 322-332

Wishnoff, R. J. (2000). Hedging your bets: L2 learners' acquisition of pragmatic devices in academic writing and computer-mediated discourse. Second Language Studies, 19(1), 119-148

Walkó. Z. (2007). EFL research articles through the lens of pragmatic politeness. WoPaLP 1, 1-16

Wanga, N., Johnson, L., Mayer, R., Rizzo, P., Shaw, E., \& Collins, P. (2007). The politeness effect: Pedagogical agents and learning outcomes. Information and Organization, 17(2), 193-231

Yian, W. (2008). A study of the speech act of complaining: Cross-cultural perspective and interlanguage perspective. Intercultural Forum, 1(2)

YenWang, A. (2009). Face-threatening acts: A dynamic perspective. California Linguistic Notes, XXXIV. 
Table 1. Complaint made to a friend who messes up speaker's room

\begin{tabular}{|l|l|l|}
\hline \multicolumn{1}{|c|}{ Component } & Complainer & Frequency of use \\
\hline 1-Below the level of reproach & Intermediate & $50 \%$ \\
& Upper & $25 \%$ \\
\hline 2-Expression of annoyance or disapproval & Intermediate & $20 \%$ \\
& Upper & $30 \%$ \\
\hline 3-Explicit complaint & Intermediate & $10 \%$ \\
& Upper & \\
\hline 4-Accusation and warning & Intermediate & $5 \%$ \\
& Upper & \\
\hline 5-Requests for repair & Intermediate & $15 \%$ \\
& Upper & $25 \%$ \\
\hline 6-Justification & Intermediate & \\
& Upper & $20 \%$ \\
\hline 7-Criticisms & Intermediate & \\
& Upper & \\
\hline
\end{tabular}

Table 2. Complaint made to stranger

\begin{tabular}{|l|l|l|}
\hline \multicolumn{1}{|c|}{ Component } & Complainer & Frequency of use \\
\hline 1-Below the level of reproach & Intermediate & $5 \%$ \\
& Upper & \\
\hline 2-Expression of annoyance or disapproval & Intermediate & $35 \%$ \\
& Upper & $20 \%$ \\
\hline 3-Explicit complaint & Intermediate & $45 \%$ \\
& Upper & $15 \%$ \\
\hline 4-Accusation and warning & Intermediate & $15 \%$ \\
& Upper & $30 \%$ \\
\hline 5-Requests for repair & Intermediate & \\
& Upper & $30 \%$ \\
\hline 6-Justification & Intermediate & \\
& Upper & $5 \%$ \\
\hline 7-Criticisms & Intermediate & \\
& Upper & \\
\hline
\end{tabular}


Table 3. Complaint to the boss

\begin{tabular}{|l|l|l|}
\hline \multicolumn{1}{|c|}{ Component } & Complainer & Frequency of use \\
\hline 1-Below the level of reproach & $\begin{array}{l}\text { Intermediate } \\
\text { Upper }\end{array}$ & $\begin{array}{l}5 \% \\
5 \%\end{array}$ \\
\hline 2-Expression of annoyance or disapproval & $\begin{array}{l}\text { Intermediate } \\
\text { Upper }\end{array}$ & $\begin{array}{l}30 \% \\
30 \%\end{array}$ \\
\hline 3-Explicit complaint & $\begin{array}{l}\text { Intermediate } \\
\text { Upper }\end{array}$ & $20 \%$ \\
\hline 4-Accusation and warning & Intermediate & $15 \%$ \\
\hline 5-Requests for repair & Upper & \\
\hline 6-Justification & Intermediate & $30 \%$ \\
& Upper & $40 \%$ \\
\hline 7-Criticisms & Intermediate & \\
& Upper & $25 \%$ \\
\hline
\end{tabular}

Table 4. Complaint to advisor

\begin{tabular}{|l|l|l|}
\hline \multicolumn{1}{|c|}{ Component } & Complainer & Frequency of use \\
\hline 1-Below the level of reproach & $\begin{array}{l}\text { Intermediate } \\
\text { Upper }\end{array}$ & $\begin{array}{l}20 \% \\
35 \%\end{array}$ \\
\hline 2-Expression of annoyance or disapproval & $\begin{array}{l}\text { Intermediate } \\
\text { Upper }\end{array}$ & \\
\hline 3-Explicit complaint & Intermediate & $45 \%$ \\
\hline 4-Accusation and warning & Upper & \\
\hline 5-Requests for repair & $\begin{array}{l}\text { Intermediate } \\
\text { Upper }\end{array}$ & $10 \%$ \\
& $20 \%$ \\
\hline 6-Justification & $\begin{array}{l}\text { Intermediate } \\
\text { Upper }\end{array}$ & $25 \%$ \\
& Intermediate & $35 \%$ \\
\hline 7-Criticisms & Upper & $10 \%$ \\
\hline
\end{tabular}


Table 5. Complaint to classmate

\begin{tabular}{|l|l|l|}
\hline \multicolumn{1}{|c|}{ Component } & Complainer & Frequency of use \\
\hline 1-Below the level of reproach & $\begin{array}{l}\text { Intermediate } \\
\text { Upper }\end{array}$ & $10 \%$ \\
\hline 2-Expression of annoyance or disapproval & $\begin{array}{l}\text { Intermediate } \\
\text { Upper }\end{array}$ & $40 \%$ \\
& $35 \%$ \\
\hline 3-Explicit complaint & $\begin{array}{l}\text { Intermediate } \\
\text { Upper }\end{array}$ & $25 \%$ \\
\hline 4-Accusation and warning & $\begin{array}{l}\text { Intermediate } \\
\text { Upper }\end{array}$ & $10 \%$ \\
\hline 5-Requests for repair & $\begin{array}{l}\text { Intermediate } \\
\text { Upper }\end{array}$ & $25 \%$ \\
& $45 \%$ \\
\hline 6-Justification & $\begin{array}{l}\text { Intermediate } \\
\text { Upper }\end{array}$ & $10 \%$ \\
\hline 7-Criticisms & $\begin{array}{l}\text { Intermediate } \\
\text { Upper }\end{array}$ & \\
\hline
\end{tabular}

\section{Appendix A}

Discourse Completion Test

Name:

age:

first language:

For how many years have you studied English?

There are 5 complaining situations in this paper. Please look at responses in situation 1 and write your desired answers for each situations and complete blank space in every situations.

Situation \#1.

One of your American friends is visiting you for the weekend. Before he/she arrives, you clean the kitchen. Then, you need to go to the shopping because you forgot to buy something. You tell your friend to make him/herself comfortable. When you come back home, you see that your friend has left a big mess in the kitchen.

1. No problem at all. "Ok, it is made dirty. Never mind. I don't mind"

2. In this home, we tried to keep the house clean.

3. What happened here?! I said make yourself comfortable, no make a mess!!

4. Hey,I must not allow you to come my home later.

5. Could you please clean the room before you leave?

6. I guess you were a little hungry!

7. Hey. It's very rude of you. You must consider that, it is not your room

You:

Situation \#2.

You want to buy tickets for a concert. You go to the ticket office and have to wait in a long line with other people. The tickets are almost sold out. You have been waiting in line for almost two hours. While you are standing in line, a $\mathrm{man} /$ woman who is about your age tries to cut in line in front of you.

You:

Situation \#3.

You have worked for your boss since last year. You think you get along well. Every year, your boss writes a review of your job performance. This year, you find out that your boss is giving you a bad review. You think the review is not fair.

You: 
Situation \#4.

Last fall, you registered for courses. You went to your academic advisor in order to get advice. That was the first time and the only time you met the advisor. You asked the advisor what courses you should take during the fall term. The advisor told you what courses to take. After the fall term, you find out that one of the courses was not necessary for you. Instead, you have to take a different course now during the summer term in order to fulfill the required courses.

You:

Situation\#5.

Yesterday you placed an order at the photocopy shop for 10 bound copies of your thesis. Today you must deliver all 10 copies to your evaluation committee by 12:00 noon. When you go to the photocopy shop at 11:00A.M to pick up your booklets, the clerk, whom you recognize from one of your classes, seems confused and unaware of your request.

You:

Thanks 